Article

\title{
Calcarides A-E, Antibacterial Macrocyclic and Linear Polyesters from a Calcarisporium Strain
}

\author{
Johanna Silber, Birgit Ohlendorf, Antje Labes, Arlette Erhard and Johannes F. Imhoff * \\ Kiel Center for Marine Natural Products KiWiZ, GEOMAR Helmholtz Centre for Ocean Research \\ Kiel, Am Kiel-Kanal 44, Kiel 24106, Germany; E-Mails: jsilber@geomar.de (J.S.); \\ bohlendo@gmx.de (B.O.); alabes@geomar.de (A.L.); aerhard@geomar.de (A.E.) \\ * Author to whom correspondence should be addressed; E-Mail: jimhoff@geomar.de; \\ Tel.: +49-431-600-4450; Fax: +49-431-600-4452.
}

Received: 24 July 2013; in revised form: 16 August 2013 / Accepted: 21 August 2013 /

Published: 29 August 2013

\begin{abstract}
Bioactive compounds were detected in crude extracts of the fungus, Calcarisporium sp. KF525, which was isolated from German Wadden Sea water samples. Purification of the metabolites from the extracts yielded the five known polyesters, $15 \mathrm{G} 256 \alpha, \alpha-2, \beta, \beta-2$ and $\pi(\mathbf{1}-\mathbf{5})$, and five new derivatives thereof, named calcarides $\mathrm{A}-\mathrm{E}$ $(6-10)$. The chemical structures of the isolated compounds were elucidated on the basis of one- and two-dimensional NMR spectroscopy supported by UV and HRESIMS data. The compounds exhibited inhibitory activities against Staphylococcus epidermidis, Xanthomonas campestris and Propionibacterium acnes. As the antibacterial activities were highly specific with regard to compound and test strain, a tight structure-activity relationship is assumed.
\end{abstract}

Keywords: fungal natural products; Calcarisporium sp.; calcarides A-E; 15G256 components; macrocyclic and linear polyesters; antibacterial activities; antibiotic; marine natural products

\begin{abstract}
Abbreviations
NMR, nuclear magnetic resonance; HRESIMS, high-resolution electrospray ionization mass spectrometry; HPLC, high-performance liquid chromatography; MS, mass spectrometry; ESIMS, electrospray ionization mass spectrometry; DEPT, distortionless enhancement by polarization transfer;
\end{abstract}


COSY, correlation spectroscopy; HSQC, heteronuclear single-quantum coherence; HMBC, heteronuclear multiple bond correlation; Mult., multiplicity; ESI, electrospray ionization; calcd, calculated; SI, supplementary information; $\mathrm{OD}_{600}$, optical density at $600 \mathrm{~nm}$; DMSO, dimethyl sulfoxide; PYG medium, peptone yeast glucose medium; DSMZ, German collection of microorganisms and cell cultures.

\section{Introduction}

Fungal species of the genus, Calcarisporium, have a widespread occurrence and are frequently found as mycoparasites or symbiotes of higher fungi [1-5]. The Calcarisporium sp. strain KF525 investigated in this study was isolated from a water sample taken in the German Wadden Sea. It showed a diverse chemical profile, including ten structurally closely related compounds of the 15G256-type known as, e.g., 15G256 (1) or $\alpha$-2 (2) (Figure 1; to be differentiated from the structural class comprising $15 \mathrm{G} 256 \gamma, \delta$ and $\varepsilon$ ).

Figure 1. Compounds isolated from Calcarisporium sp. KF525: 15G256 $\alpha, \alpha-2, \beta, \beta-2$ and $\pi(\mathbf{1}-\mathbf{5})$ and calcarides A-E (6-10).

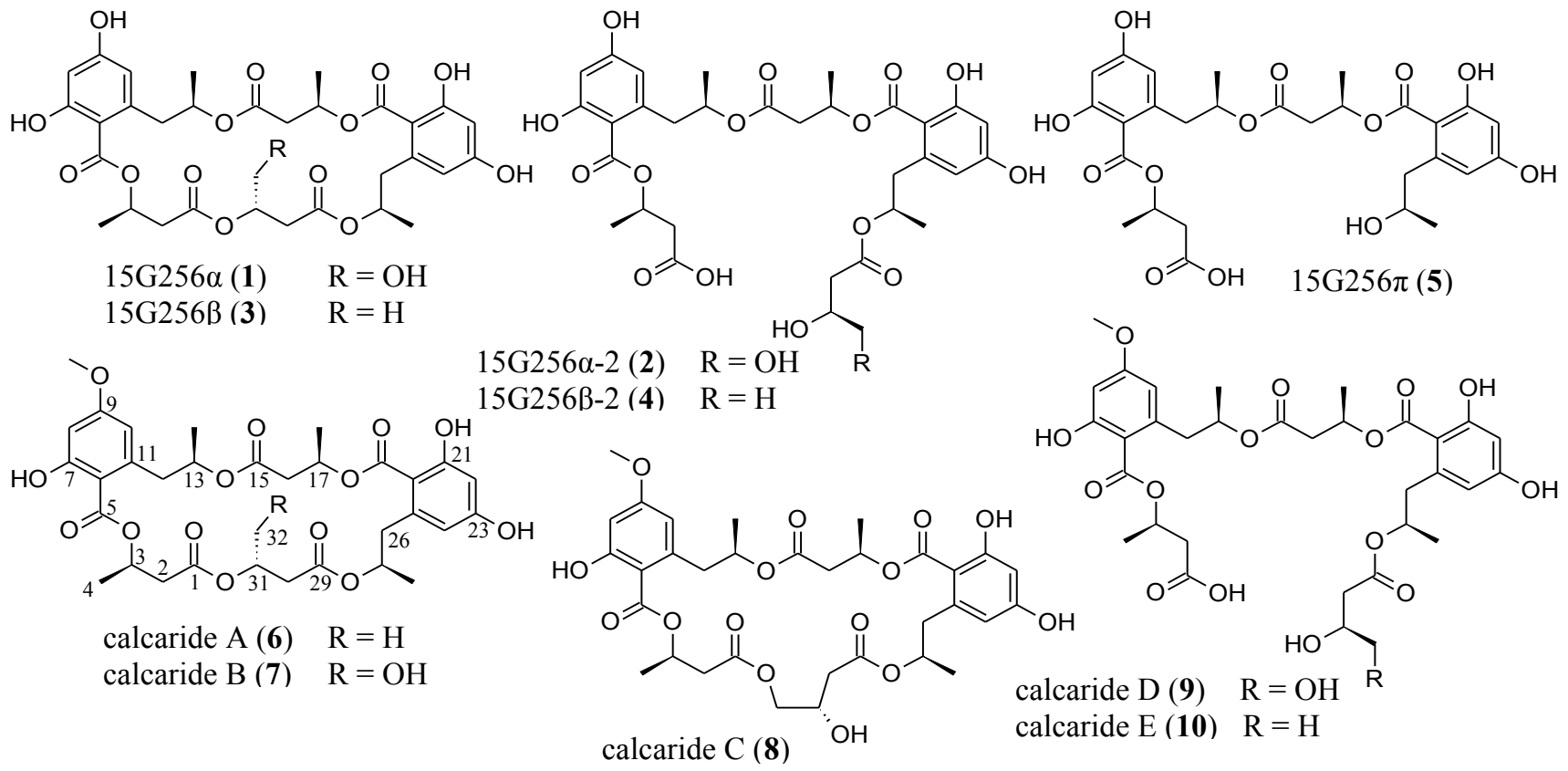

The 15G256-type compounds are produced by a number of fungi, such as ascomycetes, like Hypoxylon, Penicillium, Talaromyces, Acremonium and Scedosporium species, as well as by the basidiomycete, Albatrellus confluens [6-12]. Since some metabolites were isolated independently from the different producer strains, renaming occurred among the 15G256-type compounds. 15G256 $\alpha$ (1) is synonymous with BK233-A and NG-012, 15G256 $\alpha-1$ is a synonym of BK233-B and probably NG-011 (discussed in [6]), while 15G256ß (3) was also named orbuticin, BK233-C and BE-26263 [6,7,9,10,13]. With regard to the chemical structures, the compounds are polyesters that occur either in closed ring structures as macrocycles or as linear molecules (Figure 1). Schlingmann et al. proposed a biosynthesis route in which 6-hydroxymellein and $\beta$-hydroxybutyric acid (Figure 2) are the precursors of the $15 \mathrm{G} 256$ components, forming the acyclic polyesters in the first instance. In later 
biosynthetic steps, the macrocyclic 15G256 compounds arise from the linear polyesters by ring closure reactions [6]. Various biological activities have been ascribed to the 15G256 agents, including antifungal, estrogenic and cytotoxic properties, as well as they were shown to potentiate nerve growth factor-induced neurite outgrowth [6-10]. For example, 15G256 $\alpha$ (1), $\alpha-1$ and $\beta$ (3) attracted attention in the field of crop protection, as they displayed antifungal properties against important plant pathogenic fungi, e.g., Botrytis cinerea or Monilinia fructigena [7].

Here, we report the isolation of five known (1-5) and five new (6-10) 15G256-type compounds from Calcarisporium sp. strain KF525. Their structure elucidation and antibacterial activities are described.

Figure 2. Proposed biosynthetic precursors of the calcarides (based on the proposal of Schlingmann et al. [6]).

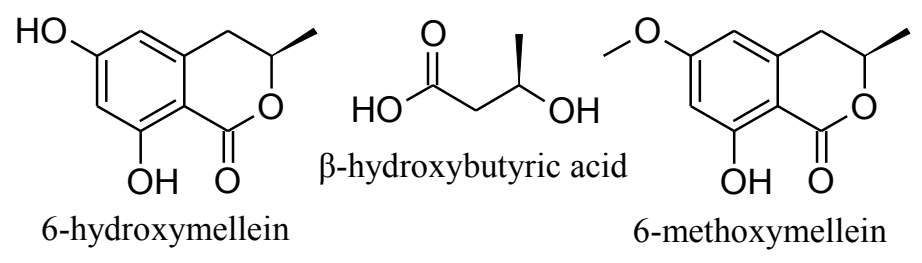

\section{Results and Discussion}

\subsection{Isolation and Structure Elucidation}

The fungal strain KF525 is a Calcarisporium sp. that is a part of the marine fungal strain collection of the Kiel Center for Marine Natural Products [14]. Extracts of cultures from the Calcarisporium sp. strain KF525 grown in modified casamino acids glucose medium [15] showed antibacterial activities and were investigated in detail. Fractionation of these extracts by preparative reversed-phase HPLC yielded the known compounds, $15 \mathrm{G} 256 \alpha, \alpha-2, \beta, \beta-2$ and $\pi(\mathbf{1}-\mathbf{5})$, as well as five new derivatives thereof, calcarides A-E (6-10) (Figure 1).

The structures of 1-5 were identified by comparison of their spectroscopic data (UV, MS and ${ }^{1} \mathrm{H}$ NMR spectra) with those described in the literature [6]. As the data agreed well with the values published, the structures of $\mathbf{1}-\mathbf{5}$ were assigned as shown in Figure 1.

The molecular formula of calcaride A (6) was determined to be $\mathrm{C}_{33} \mathrm{H}_{40} \mathrm{O}_{14}$ by high-resolution ESIMS measurements (measured 661.2503, calculated 661.2491 $[\mathrm{M}+\mathrm{H}]^{+}$). The structure of 6 was elucidated on the basis of one- and two-dimensional NMR spectra $\left({ }^{1} \mathrm{H},{ }^{13} \mathrm{C}, \mathrm{DEPT}, \mathrm{COSY}, \mathrm{HSQC}\right.$ and HMBC, see Table 1). The NMR spectra of 6 were measured in acetone- $d_{6}$, as it did not dissolve well in methanol- $d_{4}$, whereas NMR data of all other calcarides were recorded in methanol- $d_{4}$. The analysis of the NMR data of 6 revealed considerable structural similarities with $15 \mathrm{G} 256 \beta$ (3). The ${ }^{1} \mathrm{H}$ NMR spectrum, the ${ }^{1} \mathrm{H}$ NMR coupling constants and the ${ }^{13} \mathrm{C}$ NMR spectrum of $\mathbf{6}$ showed that, comparable to 3 [6,7], the compound was composed of two phenyl moieties with their two protons in meta position to each other and five methyl, five methylene, five methine and five ester carbonyl groups. The two-dimensional NMR spectra of $\mathbf{6}$ proved that the aforementioned functional groups were connected exactly as in 3, forming a cyclic pentalactone. A mass difference of 14 between $\mathbf{6}$ and $\mathbf{3}$ indicated the presence of an additional methyl group in $\mathbf{6}$, which was corroborated by additional signals for a methyl group in the ${ }^{1} \mathrm{H}$ and ${ }^{13} \mathrm{C}$ NMR spectra. The chemical shifts of the respective proton and carbon 
resonances $\left(\delta_{\mathrm{H}} 3.82 \mathrm{ppm}, \delta_{\mathrm{C}} 55.8 \mathrm{ppm}\right)$ determined it to be a methoxy group. The proton signal of the methoxy group correlated with $\mathrm{C}-9$ in the HMBC NMR spectrum. Thus, the structure of 6 was identified as the methylated derivative of $\mathbf{3}$, with the methyl group attached to the hydroxyl group of C-9.

Table 1. NMR spectroscopic data (500 MHz, acetone- $d_{6}$ ) of calcaride A (6).

\begin{tabular}{|c|c|c|c|c|}
\hline Position & $\delta_{\mathrm{C}}$, Type & $\delta_{\mathrm{H}}$, Mult. $(J$ in Hz) & COSY & HMBC \\
\hline 1 & $170.09, \mathrm{C}$ & & & \\
\hline $2 \mathrm{a}$ & $40.6, \mathrm{CH}_{2}$ & $2.91, \mathrm{dd}(6.7,16.3)$ & $2 b, 3$ & $1,3,4$ \\
\hline $2 b$ & & $2.74, \mathrm{dd}(6.4,16.3)$ & $2 \mathrm{a}, 3$ & $1,3,4$ \\
\hline 3 & $70.1, \mathrm{CH}^{\mathrm{a}}$ & $5.56, \mathrm{~m}$ & $2 \mathrm{a}, 2 \mathrm{~b}, 4$ & $1,2,4,5$ \\
\hline 4 & $20.0, \mathrm{CH}_{3}$ & $1.450, \mathrm{~d}(6.4)$ & 3 & $1,2,3$ \\
\hline 5 & $171.0, \mathrm{C}$ & & & \\
\hline 6 & $106.9, \mathrm{C}$ & & & \\
\hline 7 & $165.5, \mathrm{C}$ & & & \\
\hline 8 & $100.4, \mathrm{CH}$ & $6.36, \mathrm{~d}(2.6)$ & 10 & $5,6,7,9,10$ \\
\hline 9 & $164.8, \mathrm{C}$ & & & \\
\hline $\mathrm{OCH}_{3}$ & $55.8, \mathrm{CH}_{3}$ & $3.82, \mathrm{~s}$ & & 9 \\
\hline 10 & $111.9, \mathrm{CH}$ & $6.44, \mathrm{~d}(2.6)$ & 8 & $5,6,8,9,12$ \\
\hline 11 & $142.9, \mathrm{C}$ & & & \\
\hline $12 \mathrm{a}$ & 41.7, $\mathrm{CH}_{2}$ & $3.547, \mathrm{dd}(6.8,13.3)$ & $12 b, 13$ & $6,10,11,13,14$ \\
\hline $12 b$ & & $2.98, \mathrm{dd}(7.5,13.3)$ & $12 \mathrm{a}, 13$ & $6,10,11,13,14$ \\
\hline 13 & $73.1, \mathrm{CH}$ & $5.05, \mathrm{~m}^{\mathrm{b}}$ & $12 \mathrm{a}, 12 \mathrm{~b}, 14$ & $11,12,14,15$ \\
\hline 14 & 19.7, $\mathrm{CH}_{3}$ & $1.19, \mathrm{~d}(6.2)$ & 13 & 12,13 \\
\hline 15 & $170.12, \mathrm{C}$ & & & \\
\hline $16 \mathrm{a}$ & $41.02, \mathrm{CH}_{2}$ & $2.90, \mathrm{dd}(6.3,15.8)$ & $16 \mathrm{~b}, 17$ & $15,17,18$ \\
\hline $16 \mathrm{~b}$ & & $2.72, \mathrm{dd}(7.1,15.8)$ & $16 a, 17$ & $15,17,18$ \\
\hline 17 & $70.0, \mathrm{CH}^{\mathrm{a}}$ & $5.52, \mathrm{~m}$ & $16 a, 16 b, 18$ & $15,16,18,19$ \\
\hline 18 & $20.1, \mathrm{CH}_{3}$ & $1.454, \mathrm{~d}(6.4)$ & 17 & $15,16,17$ \\
\hline 19 & $170.9, \mathrm{C}$ & & & \\
\hline 20 & 105.6, C & & & \\
\hline 21 & $165.9, \mathrm{C}$ & & & \\
\hline 22 & $102.6, \mathrm{CH}$ & $6.30, \mathrm{~d}(2.5)$ & 24 & $19,20,21,23,24$ \\
\hline 23 & $163.1, \mathrm{C}$ & & & \\
\hline 24 & 113.3, $\mathrm{CH}$ & $6.35, \mathrm{~d}(2.5)$ & 22 & $19,20,22,23,26$ \\
\hline 25 & $143.3, \mathrm{C}$ & & & \\
\hline $26 a$ & $42.4, \mathrm{CH}_{2}$ & $3.553, \mathrm{dd}(5.7,12.9)$ & $26 \mathrm{~b}, 27$ & $20,24,25,27,28$ \\
\hline $26 \mathrm{~b}$ & & $2.78, \mathrm{dd}(8.6,12.9)$ & $26 a, 27$ & $20,24,25,27,28$ \\
\hline 27 & $72.5, \mathrm{CH}$ & $5.01, \mathrm{~m}^{\mathrm{b}}$ & $26 \mathrm{a}, 26 \mathrm{~b}, 28$ & $25,26,28,29$ \\
\hline 28 & $19.5, \mathrm{CH}_{3}$ & $1.14, \mathrm{~d}(6.2)$ & 27 & 26,27 \\
\hline 29 & $170.2, \mathrm{C}$ & & & \\
\hline $30 \mathrm{a}$ & $41.01, \mathrm{CH}_{2}$ & $2.63^{\mathrm{c}}$ & $30 \mathrm{~b}, 31$ & $29,31,32$ \\
\hline $30 \mathrm{~b}$ & & $2.63^{c}$ & $30 \mathrm{a}, 31$ & $29,31,32$ \\
\hline 31 & $68.4, \mathrm{CH}$ & $5.28, \mathrm{~m}$ & $30 \mathrm{a}, 30 \mathrm{~b}, 32$ & $1,29,30,32$ \\
\hline 32 & $19.9, \mathrm{CH}_{3}$ & $1.27, \mathrm{~d}(6.3)$ & 31 & $29,30,31$ \\
\hline
\end{tabular}

${ }^{a}$ Assignments of C-3 and C-17 are interchangeable; ${ }^{b}$ signals overlap and are deduced from the HSQC NMR spectrum; ${ }^{\mathrm{c}}$ signals overlap. 
The molecular formula of calcaride B (7) was deduced to be $\mathrm{C}_{33} \mathrm{H}_{40} \mathrm{O}_{15}$ by high-resolution ESIMS measurements (measured 677.2435, calculated 677.2440[M+H] ${ }^{+}$). UV and NMR spectra of 7 (Tables 2 and 3) strongly resembled those of 6 . The NMR spectra of 7 showed all resonances as those of 6, apart from one striking difference: the signals in position 32 corresponded to a methylene instead of a methyl group. The downfield shift of the proton and carbon signals of $\mathrm{CH}_{2}-32\left(\delta_{\mathrm{H}} 3.65\right.$ and $3.58 \mathrm{ppm}, \delta_{\mathrm{C}} 63.6 \mathrm{ppm}$ ) suggested the attachment of a hydroxyl group to C-32 in 7. This was in full accordance with a mass increase of 16 mass units in comparison to 6 and determined 7 to be the methylated analog of the known compound, $15 \mathrm{G} 256 \alpha(\mathbf{1})$.

Table 2. ${ }^{1} \mathrm{H}$ NMR spectroscopic data of calcarides A-C (6-8) $\left(500 \mathrm{MHz}\right.$, acetone- $d_{6}$ for 6; $500 \mathrm{MHz}$, methanol- $d_{4}$ for 7-8).

\begin{tabular}{|c|c|c|c|}
\hline Position & $\begin{array}{l}\text { Calcaride A (6) } \\
\delta_{\mathrm{H}}, \text { Mult. }(J \text { in } \mathrm{Hz})\end{array}$ & $\begin{array}{l}\text { Calcaride B (7) } \\
\delta_{\mathrm{H}} \text {, Mult. ( } J \text { in Hz) }\end{array}$ & $\begin{array}{l}\text { Calcaride C (8) } \\
\delta_{\mathrm{H}}, \text { Mult. }(J \text { in Hz) }\end{array}$ \\
\hline $2 \mathrm{a}$ & $2.91, \mathrm{dd}(6.7,16.3)$ & $2.88, \mathrm{dd}(7.7,16.6)$ & $2.878, \mathrm{dd}(8.1,16.2)$ \\
\hline $2 b$ & $2.74, \mathrm{dd}(6.4,16.3)$ & $2.73, \mathrm{~d}(5.3,16.6)$ & $2.79, \mathrm{dd}(4.8,16.2)$ \\
\hline 3 & $5.56, \mathrm{~m}$ & $5.56, \mathrm{~m}$ & $5.59, \mathrm{~m}$ \\
\hline 4 & $1.450, \mathrm{~d}(6.4)$ & $1.42, \mathrm{~d}(6.3)$ & $1.44, \mathrm{~d}(6.4)$ \\
\hline 8 & $6.36, \mathrm{~d}(2.6)$ & $6.30, \mathrm{~d}(2.6)$ & $6.31, \mathrm{~d}(2.6)$ \\
\hline $\mathrm{OCH}_{3}$ & $3.82, \mathrm{~s}$ & $3.75, \mathrm{~s}$ & $3.74, \mathrm{~s}^{\mathrm{a}}$ \\
\hline 10 & $6.44, \mathrm{~d}(2.6)$ & $6.36, \mathrm{~d}(2.6)$ & $6.35, \mathrm{~d}(2.6)$ \\
\hline $12 \mathrm{a}$ & $3.547, \mathrm{dd}(6.8,13.3)$ & $3.34^{\mathrm{b}}$ & $3.35^{\mathrm{c}}$ \\
\hline $12 b$ & $2.98, \mathrm{dd}(7.5,13.3)$ & $2.96, \mathrm{dd}(6.4,13.8)$ & $2.99, \mathrm{dd}(6.6,14.0)$ \\
\hline 13 & $5.05, \mathrm{~m}^{\mathrm{d}}$ & $5.07, \mathrm{~m}$ & $5.16, \mathrm{~m}$ \\
\hline 14 & $1.19, \mathrm{~d}(6.2)$ & $1.20, \mathrm{~d}(6.2)$ & $1.22, \mathrm{~d}(6.2)$ \\
\hline $16 a$ & $2.90, \mathrm{dd}(6.3,15.8)$ & $2.81, \mathrm{dd}(7.6,15.8)$ & $2.85, \mathrm{dd}(6.6,16.0)$ \\
\hline $16 b$ & $2.72, \mathrm{dd}(7.1,15.8)$ & $2.67, \mathrm{dd}(5.7,15.8)$ & 2.69, dd $(6.6,16.0)$ \\
\hline 17 & $5.52, \mathrm{~m}$ & $5.49, \mathrm{~m}$ & $5.48, \mathrm{~m}$ \\
\hline 18 & $1.454, \mathrm{~d}(6.4)$ & $1.40, \mathrm{~d}(6.4)$ & $1.39, \mathrm{~d}(6.3)$ \\
\hline 22 & $6.30, \mathrm{~d}(2.5)$ & $6.22, \mathrm{~s}$ & $6.21, \mathrm{~d}(2.5)$ \\
\hline 24 & $6.35, \mathrm{~d}(2.5)$ & $6.22, \mathrm{~s}$ & $6.23, \mathrm{~d}(2.5)$ \\
\hline $26 a$ & $3.553, \mathrm{dd}(5.7,12.9)$ & $3.32^{\mathrm{b}}$ & $3.31^{\mathrm{c}}$ \\
\hline $26 b$ & $2.78, \mathrm{dd}(8.6,12.9)$ & $2.77, \mathrm{dd}(8.1,13.3)$ & $2.885, \mathrm{dd}(6.9,13.4)$ \\
\hline 27 & $5.01, \mathrm{~m}^{\mathrm{d}}$ & $4.98, \mathrm{~m}$ & $5.03, \mathrm{~m}$ \\
\hline 28 & $1.14, \mathrm{~d}(6.2)$ & $1.11, \mathrm{~d}(6.2)$ & $1.16, \mathrm{~d}(6.2)$ \\
\hline $30 a$ & $2.63^{\mathrm{e}}$ & $2.68, \mathrm{dd}(5.1,16.7)$ & $2.51, \mathrm{dd}(6.0,15.3)$ \\
\hline $30 \mathrm{~b}$ & $2.63^{\mathrm{e}}$ & $2.64, \mathrm{dd}(8.1,16.7)$ & $2.43, \mathrm{dd}(7.2,15.3)$ \\
\hline 31 & $5.28, \mathrm{~m}$ & $5.28, \mathrm{~m}$ & $4.17, \mathrm{~m}$ \\
\hline $32 \mathrm{a}$ & $1.27, \mathrm{~d}(6.3)$ & $3.65, \mathrm{dd}(4.5,11.9)$ & $4.12, \mathrm{dd}(4.8,11.1)$ \\
\hline $32 b$ & & $3.58, \mathrm{dd}(5.1,11.9)$ & $4.08, \mathrm{dd}(5.5,11.1)$ \\
\hline
\end{tabular}

${ }^{a}$ Position of the methoxy group could not unambiguously be determined. In analogy to the other calcarides, it was assumed to be linked to C-9. ${ }^{b}$ Signal partially obscured and deduced from the HMBC NMR spectrum; ${ }^{\mathrm{c}}$ signal partially obscured; ${ }^{\mathrm{d}}$ signals overlap and are deduced from the HSQC NMR spectrum; ${ }^{\mathrm{e}}$ signals overlap.

Calcaride $\mathrm{C}(\mathbf{8})$ was found to have a molecular formula of $\mathrm{C}_{33} \mathrm{H}_{40} \mathrm{O}_{15}$ by means of high-resolution ESIMS measurements (measured 677.2441, calculated 677.2440 [M+ H] $]^{+}$). Thus, 7 and 8 had the 
same molecular formula, showing that the closely related compounds were structural isomers, as was confirmed by comparison of the NMR spectra of the two compounds (Tables 2 and 3). For two of the known 15G256 components, 15G256 (1) and 15G256 $\alpha$-1 (Figure 3), a comparable regioisomerism was observed in which either $\beta$ - or $\gamma$-hydroxyester linkages lead to the ring closure of the compound [6].

Table 3. ${ }^{13} \mathrm{C}$ NMR shifts of calcarides A-E (6-10) $\left(125 \mathrm{MHz}\right.$, acetone- $d_{6}$ for $\mathbf{6} ; 125 \mathrm{MHz}$, methanol- $d_{4}$ for 7-9; $150 \mathrm{MHz}$, methanol- $d_{4}$ for 10).

\begin{tabular}{|c|c|c|c|c|c|}
\hline & Calcaride A (6) & Calcaride B (7) & Calcaride C (8) & Calcaride D (9) & Calcaride E (10) \\
\hline Position & $\boldsymbol{\delta}_{\mathrm{C}}$ & $\boldsymbol{\delta}_{\mathrm{C}}$ & $\boldsymbol{\delta}_{\mathbf{C}}$ & $\boldsymbol{\delta}_{\mathrm{C}}$ & $\boldsymbol{\delta}_{\mathbf{C}}$ \\
\hline 1 & 170.09 & $171.5^{\mathrm{a}}$ & 171.6 & $173.9^{b}$ & $175.9^{b}$ \\
\hline 2 & 40.6 & 41.0 & 41.2 & 41.8 & 43.3 \\
\hline 3 & $70.1^{\mathrm{c}}$ & 70.2 & 70.5 & 70.8 & 71.5 \\
\hline 4 & 20.0 & 20.2 & 20.2 & 20.1 & 20.3 \\
\hline 5 & 171.0 & 171.13 & $171.53^{d}$ & $171.5^{\mathrm{e}}$ & $171.56^{\mathrm{f}}$ \\
\hline 6 & 106.9 & 108.7 & 108.2 & 107.2 & 107.3 \\
\hline 7 & 165.5 & 164.6 & $165.08^{\mathrm{g}, \mathrm{h}}$ & $166.0^{\mathrm{i}}$ & $166.0^{\mathrm{j}}$ \\
\hline 8 & 100.4 & 100.7 & 100.7 & 100.8 & 100.8 \\
\hline 9 & 164.8 & 164.9 & $165.0^{\mathrm{h}}$ & $165.0^{\mathrm{i}}$ & $165.0^{\mathrm{j}}$ \\
\hline $\mathrm{OCH}_{3}$ & 55.8 & 55.8 & $55.8^{\mathrm{k}}$ & 55.9 & 55.9 \\
\hline 10 & 111.9 & 111.5 & 111.3 & 112.8 & 112.8 \\
\hline 11 & 142.9 & 142.6 & 142.7 & 143.2 & 143.3 \\
\hline 12 & 41.7 & 41.8 & 41.7 & 43.2 & 43.4 \\
\hline 13 & 73.1 & 73.6 & 73.2 & 73.1 & 73.2 \\
\hline 14 & 19.7 & 20.0 & 20.0 & 20.52 & 20.6 \\
\hline 15 & 170.12 & $171.37^{\mathrm{a}}$ & $171.3^{\mathrm{d}}$ & 171.2 & 171.2 \\
\hline 16 & 41.02 & 41.6 & $41.6^{1}$ & 41.8 & 41.8 \\
\hline 17 & $70.0^{\mathrm{c}}$ & 70.4 & 70.3 & 70.0 & 70.0 \\
\hline 18 & 20.1 & 20.2 & 20.1 & 19.9 & 19.9 \\
\hline 19 & 170.9 & 171.07 & $171.48^{\mathrm{d}}$ & $171.6^{\mathrm{e}}$ & $171.62^{f}$ \\
\hline 20 & 105.6 & 106.7 & 107.3 & 105.8 & 105.7 \\
\hline 21 & 165.9 & 165.4 & $165.14^{\mathrm{g}}$ & 166.2 & 166.3 \\
\hline 22 & 102.6 & 102.8 & 102.7 & 102.7 & 102.7 \\
\hline 23 & 163.1 & 163.5 & 163.4 & 163.5 & 163.6 \\
\hline 24 & 113.3 & 113.3 & 112.6 & 113.8 & 113.9 \\
\hline 25 & 143.3 & 143.2 & 143.1 & 143.7 & 143.7 \\
\hline 26 & 42.4 & 42.3 & $41.5^{1}$ & 43.5 & 43.6 \\
\hline 27 & 72.5 & 73.5 & 73.6 & 72.7 & 72.6 \\
\hline 28 & 19.5 & 19.5 & 19.8 & 20.49 & 20.6 \\
\hline 29 & 170.2 & $171.43^{\mathrm{a}}$ & 171.9 & 172.7 & 172.5 \\
\hline 30 & 41.01 & 36.7 & 40.4 & 39.9 & 45.1 \\
\hline 31 & 68.4 & 72.7 & 67.1 & 69.9 & 65.4 \\
\hline 32 & 19.9 & 63.6 & 68.5 & 66.4 & 23.0 \\
\hline
\end{tabular}


Figure 3. Structure of $15 \mathrm{G} 256 \alpha-1[6]$.

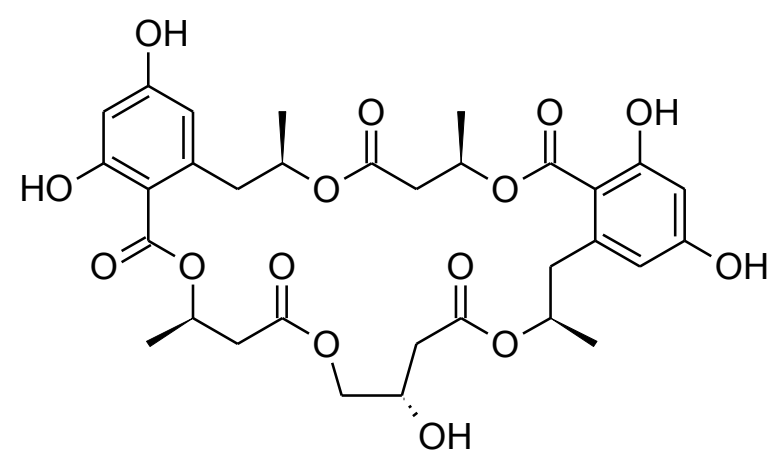

Given that $\mathbf{7}$ is the methylated form of $\mathbf{1}$, it was assumed that $\mathbf{8}$ was the methylated derivative of 15G256 $\alpha-1$. The NMR spectra of 8 confirmed the assumption, since the signals were in good agreement with those reported for $15 \mathrm{G} 256 \alpha-1$ [6]. An additional resonance for a methoxy group in the NMR spectra of 8 determined it to be the methyl ether of $15 \mathrm{G} 256 \alpha-1$. As the assignments of C-7 $\left(\delta_{\mathrm{C}} 165.08 \mathrm{ppm}\right)$ and $\mathrm{C}-9\left(\delta_{\mathrm{C}} 165.0 \mathrm{ppm}\right)$ might be interchangeable, the position of the methoxy group that showed a correlation to either of the two signals in the HMBC spectrum could not unambiguously be determined. In analogy to $6,7,9$ and 10 , where the methyl group was linked to the hydroxyl group of $\mathrm{C}-9$, it was deduced that this is also most likely to be the case for compound $\mathbf{8}$. In addition to being regioisomers, it was observed that $\mathbf{7}$ and $\mathbf{8}$ interconverted during storage as dried compounds, with $\mathbf{7}$ showing a purity of about $75 \%$ after a period of two weeks. At the same time, compound 8 had converted into 7 more slowly and showed a purity of around $85 \%$. These percentages were stable over a period of three months in which the compound stability was studied.

The molecular formula of calcaride D (9) was determined as $\mathrm{C}_{33} \mathrm{H}_{42} \mathrm{O}_{16}$ on the basis of high-resolution ESIMS measurements (measured 693.2405, calculated $693.2400[\mathrm{M}-\mathrm{H}]^{-}$), requiring 13 degrees of unsaturation. The NMR spectra of 9 (Tables 3 and 4) showed signals for the two phenolic substructures characteristic of the calcarides and five carbonyl resonances, together accounting for 13 double bond equivalents. These data suggested a ring opening for 9, giving the structure of a linear polyester, as has been found among the 15G256 components, as well, e.g., 15G256 $\alpha-2$ (2), $\beta$-2 (4) and $\pi$ (5). MS and NMR spectra proved 9 to be the methylated analog of 2 . For the linear calcarides ( 9 and 10), the NMR spectra recorded in methanol- $d_{4}$ gave one single signal for the aromatic protons of $\mathrm{H}-8$ and $\mathrm{H}-10\left(\delta_{\mathrm{H}} 6.33 \mathrm{ppm}\right)$. Therefore, the position of the carbon signals of C-7 and C-9 ( $\delta_{\mathrm{C}} 166.0$ and $\left.165.0 \mathrm{ppm}\right)$ could not be differentiated by the HMBC correlations of the aromatic protons resonances. As a consequence, the methoxy group showing a clear HMBC correlation to the signal at $165.0 \mathrm{ppm}$ could have been attached to either C-7 or C-9. In order to determine the position of the methoxy group of 9, additional NMR spectra were recorded in chloroform- $d_{1}$ in which signals of H-8 and H-10 appeared separately. The HMBC NMR spectrum displayed correlations of H-8 to C-7 and C-9 and of H-10 to C-9 and C-12. Thereby, the positions of the signals for C-7 and C-9 could be assigned. Consequently, the methoxy group for which the HMBC NMR spectrum displayed a correlation to the resonance of C-9 had to be attached to C-9, as shown in Figure 1. 
Table 4. ${ }^{1} \mathrm{H}$ NMR spectroscopic data of calcarides D and $\mathrm{E}(\mathbf{9}$ and 10) $(500 \mathrm{MHz}$, methanol- $d_{4}$ for 9; $600 \mathrm{MHZ}$, methanol- $d_{4}$ for 10).

\begin{tabular}{lll}
\hline & Calcaride D (9) & Calcaride E (10) \\
Position & $\boldsymbol{\delta}_{\mathbf{H}}$, Mult. $(\boldsymbol{J}$ in Hz) & $\boldsymbol{\delta}_{\mathbf{H}}$, Mult. $(\boldsymbol{J}$ in Hz) \\
\hline $2 \mathrm{a}$ & $2.767, \mathrm{dd}(7.5,15.8)$ & $2.72, \mathrm{dd}(7.8,15.4)$ \\
$2 \mathrm{~b}$ & $2.69, \mathrm{dd}(5.3,15.8)$ & $2.61, \mathrm{dd}(5.9,15.4)^{\mathrm{a}}$ \\
3 & $5.57, \mathrm{~m}$ & $5.58, \mathrm{~m}$ \\
4 & $1.43, \mathrm{~d}(6.4)$ & $1.43, \mathrm{~d}(6.3)$ \\
8 & $6.33, \mathrm{~s}$ & $6.33, \mathrm{~s}$ \\
$\mathrm{OCH}_{3}$ & $3.77, \mathrm{~s}$ & $3.77, \mathrm{~s}$ \\
10 & $6.33, \mathrm{~s}$ & $6.33, \mathrm{~s}$ \\
$12 \mathrm{a}$ & $3.29 \mathrm{~b}$ & $3.35, \mathrm{dd}(3.5,13.6)^{\mathrm{a}}$ \\
$12 \mathrm{~b}$ & $2.91, \mathrm{dd}(9.7,13.7)$ & $2.87, \mathrm{dd}(9.8,13.6)$ \\
13 & $5.22, \mathrm{~m}$ & $5.22, \mathrm{~m}$ \\
14 & $1.25, \mathrm{~d}(6.2)$ & $1.26, \mathrm{~d}(6.3)$ \\
$16 \mathrm{a}$ & $2.66, \mathrm{dd}(7.2,15.7)$ & $2.65, \mathrm{dd}(7.2,15.6)$ \\
$16 \mathrm{~b}$ & $2.62, \mathrm{dd}(5.8,15.7)$ & $2.62, \mathrm{dd}(6.0,15.6)$ \\
17 & $5.47, \mathrm{~m}$ & $5.47, \mathrm{~m}$ \\
18 & $1.30, \mathrm{~d}(6.4)$ & $1.30, \mathrm{~d}(6.3)$ \\
22 & $6.203, \mathrm{~d}(2.6)$ & $6.19, \mathrm{~d}(2.5)$ \\
24 & $6.197, \mathrm{~d}(2.6)$ & $6.18, \mathrm{~d}(2.5)$ \\
$26 \mathrm{a}$ & $3.17, \mathrm{dd}(4.0,13.4)$ & $3.20, \mathrm{dd}(3.8,13.5)$ \\
$26 \mathrm{~b}$ & $2.772, \mathrm{dd}(9.2,13.4)$ & $2.74, \mathrm{dd}(9.5,13.5)$ \\
27 & $5.15, \mathrm{~m}$ & $5.14, \mathrm{~m}$ \\
28 & $1.23, \mathrm{~d}(6.2)$ & $1.23, \mathrm{~d}(6.2)$ \\
$30 \mathrm{a}$ & $2.47, \mathrm{dd}(5.2,15.4)$ & $2.36, \mathrm{dd}(6.9,14.7)$ \\
$30 \mathrm{~b}$ & $2.27, \mathrm{dd}(7.9,15.4)$ & $2.26, \mathrm{dd}(6.5,14.7)$ \\
31 & $3.94, \mathrm{~m}$ & $4.02, \mathrm{~m}$ \\
$32 \mathrm{a}$ & $3.44, \mathrm{dd}(4.9,11.2)$ & $1.05, \mathrm{~d}(6.2)$ \\
\hline $\mathrm{b}$ & $3.40, \mathrm{dd}(5.7,11.2)$ & \\
\hline & $5 \mathrm{~s}$ & \\
\hline & &
\end{tabular}

${ }^{a}$ Signal partially obscured; ${ }^{b}$ signal partially obscured and is deduced from the HSQC NMR spectrum.

The molecular formula of calcaride $\mathrm{E}$ (10) was determined to be $\mathrm{C}_{33} \mathrm{H}_{42} \mathrm{O}_{15}$ by high-resolution ESIMS measurements (measured 677.2467, calculated 677.2451 [M - H] ${ }^{-}$). The structure of 10 was readily deduced by comparing the NMR data (Tables 3 and 4) with those of 9 . In contrast to the hydroxylated methylene group at C-32 in $\mathbf{9}$, the corresponding signals in the NMR spectra of $\mathbf{1 0}$ gave evidence for a methyl group not adjacent to oxygen. The position of the methoxy group at C-9 was determined according to additionally recorded NMR spectra in chloroform- $d_{1}$, as described for 9. Hence, the structure of $\mathbf{1 0}$ was established as the dehydroxylated form of $\mathbf{9}$, which could equivalently be described as the methylated analog of 4 .

Because 6-10 were methylated forms of known compounds, it had to be ruled out that they were artifacts arising from the extraction protocol employing methanol as the solvent. The first indication that this was not the case for 6-10 was that the four demethylated analogs 1-4, which were, as well, isolated from Calcarisporium sp. KF525, stayed demethylated when stored as methanolic solutions for time periods of more than two weeks. The final proof was that the isolation of 6-10 was likewise 
possible, when the use of methanol was avoided in all extraction steps and acetonitrile was employed instead. For this purpose, the presence of 6-10 was confirmed by using HPLC-UV/MS fingerprints of extracts from methanol and acetonitrile.

Absolute configurations of 6-10 were investigated by measurements of the optical rotation. The obtained values for optical activity were compared to those described for the demethylated analogs. The optical rotation data of $\mathbf{6}-\mathbf{8}\left([\alpha]^{22}{ }_{\mathrm{D}}-23.6,-25.3\right.$ and -7.9 , respectively) were in good agreement with the reported ones of the corresponding demethylated forms, 3, 1 and 15G256 $\alpha-1$ [6-9]. Even though some of the published values referred to ethanol solutions or higher temperatures employed for the measurements, they were consistent with our data. Hence, the absolute configurations of $\mathbf{6}-\mathbf{8}$ were suggested to be the same as for their published demethylated forms [6]. For $\mathbf{2}$ and 4, which are the demethylated derivatives of $\mathbf{9}$ and 10, there is no literature record of optical rotation values. Thus, a comparison with published data was not possible, but as $\mathbf{2}$ and $\mathbf{4}$ were also isolated from Calcarisporium sp. KF525, their optical rotation was measured $\left([\alpha]_{D}^{22}-77.8\right.$ for 2 ; $[\alpha]^{22}{ }_{D}-76.9$ for 4) and compared with the values of 9 and $\mathbf{1 0}\left([\alpha]^{22}{ }_{\mathrm{D}}-71.8\right.$ and -67.3 , respectively). As a result, the stereochemistry of $\mathbf{9}$ and $\mathbf{1 0}$ was assumed to be identical to the stereochemistry for $\mathbf{2}$ and $\mathbf{4}$ proposed by Schlingmann et al. [6] (Figure 1).

From a biosynthetic perspective, the precursors of the known $15 \mathrm{G} 256$ components are 6-hydroxymellein and $\beta$-hydroxybutyric acid [6]. Consequently, the building blocks of the calcarides should be 6-methoxymellein additional to 6-hydroxymellein and $\beta$-hydroxybutyric acid (Figure 2). 6-methoxymellein is a natural product known from a variety of fungi, e.g., Aspergillus and Ceratocystis species [16]. Both, 6-methoxy- and 6-hydroxy-mellein were found in crude extracts of Calcarisporium sp. KF525, according to UV and MS spectra from analytical HPLC-UV/MS analyses. The position of the methoxy and hydroxyl groups in the mellein structure could not be deduced from these data and was only assumed according to the position of the respective groups in the calcarides. Given that the calcarides are built up by the same or methylated precursors as the 15G256 components, the identical stereochemistry in calcaride and 15G256 molecules is reasonable.

\subsection{Antibacterial Activity}

Compounds 1-10 were profiled against a set of bacterial strains, including the biofilm-forming, Staphylococcus epidermidis, the plant pathogen, Xanthomonas campestris, and Propionibacterium acnes, which is linked to the skin disease acne. Even though the compounds are closely related from a structural point of view, they show distinct antibacterial activities (Table 5). All macrocyclic compounds $(\mathbf{1}, \mathbf{3}, \mathbf{6}-\mathbf{8})$ inhibited $S$. epidermidis and $X$. campestris, while the linear polyesters did not show any activities below a minimal inhibitory concentration (MIC) of $100 \mu \mathrm{M}$. The results indicated that a ring structure is required for the activity. This observation was also made for antifungal properties of the already known 15G256 components [6]. Among the cyclic compounds, 1 showed the highest activity against $S$. epidermidis $((12.9 \pm 3.6) \mu \mathrm{M})$, and 6 displayed the lowest MIC for $X$. campestris $((5.5 \pm 1.3) \mu \mathrm{M})$. A comparison of the inhibition between active methylated and demethylated forms, e.g. $\mathbf{1}$ and $\mathbf{7}$ or $\mathbf{3}$ and $\mathbf{6}$, showed a decreased activity against S. epidermidis by a factor of four for the methylated analogs, whereas the activities concerning $X$. campestris were in the same concentration range. $P$. acnes was not inhibited by any of the tested substances, but the linear 
compound 5. Given that $\mathbf{5}$ and $\mathbf{4}$ only differ in a $\beta$-hydroxybutyrate moiety, the $P$. acnes-related activity of $\mathbf{5}$ seemed highly specific.

Table 5. Antibacterial minimal inhibitory concentrations (MICs) of compounds $\mathbf{1}-\mathbf{1 0}$ and the positive control, chloramphenicol. Activities higher than $20 \%$ were considered as inhibitory.

\begin{tabular}{lccc}
\hline Compound & $\begin{array}{c}\text { S. epidermidis } \\
\text { MIC }[\boldsymbol{\mu M}]\end{array}$ & $\begin{array}{c}\text { X. campestris } \\
\text { MIC }[\boldsymbol{\mu M}]\end{array}$ & $\begin{array}{c}\text { P. acnes } \\
\text { MIC }[\boldsymbol{\mu M}]\end{array}$ \\
\hline $15 \mathrm{G} 256 \alpha(\mathbf{1})$ & $12.9( \pm 3.6)$ & $30.8( \pm 3.1)$ & $>100$ \\
$15 \mathrm{G} 256 \alpha-2(\mathbf{2})$ & $>150$ & $>150$ & $>200$ \\
$15 \mathrm{G} 256 \beta(\mathbf{3})$ & $16.9( \pm 0.6)$ & $14.9( \pm 7.5)$ & $>200$ \\
$16 \mathrm{G} 256 \beta-2(\mathbf{4})$ & $>150$ & $>150$ & $>100$ \\
$15 \mathrm{G} 256 \pi(\mathbf{5})$ & $>150$ & $>150$ & $14.1( \pm 1.8)$ \\
calcaride A $(\mathbf{6})$ & $68.8( \pm 3.7)$ & $5.5( \pm 1.3)$ & $>200$ \\
calcaride B (7) & $52.3( \pm 2.3)$ & $22.6( \pm 9.2)$ & $>200$ \\
calcaride C (8) & $29.6( \pm 1.6)$ & $61.4( \pm 12.7)$ & $>100$ \\
calcaride D (9) & $>150$ & $>150$ & $>200$ \\
calcaride E (10) & $104.3( \pm 7.8)$ & $>150$ & $>100$ \\
chloramphenicol & 4.5 & 1.0 & 0.5 \\
\hline
\end{tabular}

15G256 components are known to possess antifungal activities, estrogenic effects or cytotoxic properties with regard to cellular ATP (viability) and chemiluminescence (phagocytosis) in a mouse peritoneal macrophage assay, as well as they are described to be potentiators of the nerve growth factor in PC12 cells [6-10]. However, no antibacterial activities had been observed, even when tested. Here, the 15G256 compounds and the new methylated derivatives thereof were found to display antibacterial activities that are moderate in potency, but have a tight structure-activity relationship. Even a slight structural variation, like a methylation, as seen for the calcarides, influenced compound activities significantly. This was found to be true for other natural products $[17,18]$. For instance, the methylation of the cholesterol-lowering agent, lovastatin, resulted in the improved drug, simvastatin [19]. Regarding simvastatin, the introduction of a methyl group was used as a tool, but similarly, the isolation of derivatives of known compounds can be used as a strategy to obtain improved lead structures. As shown for the calcarides, fungi are a good source for this purpose, because they often produce a bunch of structurally related compounds, e.g., resulting from the promiscuity of the biosynthetic enzymes [20]. From the fungus' point of view, the production of closely-related components might be of advantage as altered activities emerge.

\section{Experimental Section}

\subsection{General Experimental Procedures}

Optical rotation measurements were obtained on a Perkin Elmer model 241 polarimeter. UV spectra were measured on a Perkin Elmer Lambda 2 photometer. NMR spectra were recorded on a Bruker DRX 500 (500 and $125 \mathrm{MHz}$ for ${ }^{1} \mathrm{H}$ and ${ }^{13} \mathrm{C} \mathrm{NMR}$, respectively) and a Bruker AV 600 spectrometer (600 and $150 \mathrm{MHz}$ for ${ }^{1} \mathrm{H}$ and ${ }^{13} \mathrm{C} \mathrm{NMR}$, respectively). The residual solvent signals were used as 
internal references for NMR analyses $\left(\delta_{\mathrm{H}} 3.31\right.$ and $\delta_{\mathrm{C}} 49.0 \mathrm{ppm}$ for methanol- $d_{4} ; \delta_{\mathrm{H}} 2.05$ and $\delta_{\mathrm{C}} 29.8 \mathrm{ppm}$ for acetone- $d_{6}, \delta_{\mathrm{H}} 7.26$ and $\delta_{\mathrm{C}} 77.2 \mathrm{ppm}$ for chloroform- $\left.d_{1}\right)$. High-resolution mass spectra were measured with a Bruker micrOTOF II, applying positive or negative ESI mode. Analytical reversed-phase HPLC-UV/MS experiments were conducted on a VWR-Hitachi LaChrom Elite system equipped with an L-2130 pump, an L-2450 diode array detector, an L-2200 autosampler, an L-2300 column oven and a Phenomenex Onyx Monolithic column $(\mathrm{C} 18,100 \times 3.00 \mathrm{~mm})$. A gradient with $0.1 \%$ formic acid in $\mathrm{H}_{2} \mathrm{O}(\mathrm{A})$ and $0.1 \%$ formic acid in acetonitrile (B) as solvents was applied: 0 min $5 \% \mathrm{~B}, 4 \mathrm{~min} 60 \% \mathrm{~B}, 6 \mathrm{~min} 100 \% \mathrm{~B}$; flow $2 \mathrm{~mL} \mathrm{~min}^{-1}$. For mass detection, the analytical HPLC system was coupled to a Bruker esquire4000 ion-trap detector. Preparative HPLC was performed on a VWR LaPrep system consisting of a P110 pump, a P311 UV detector, a Labocol Vario-2000 fraction collector (LABOMATIC), a Smartline 3900 autosampler (Knauer) and a Phenomenex Gemini-NX column $(10 \mu \mathrm{C} 18,100 \mathrm{~A}$, Axia, $100 \times 50.00 \mathrm{~mm})$. Subsequent compound purifications were performed on a Merck-Hitachi LaChrom Elite HPLC system comprised of an L-7150 pump, an L-2450 diode array detector and an L-2200 autosampler employing a reversed-phase Phenomenex Gemini-NX column $(5 \mu \mathrm{C} 18,110 \mathrm{~A}$, Axia, $100 \times 21.20 \mathrm{~mm}) .0 .1 \%$ of formic acid in $\mathrm{H}_{2} \mathrm{O}(\mathrm{A})$ and $0.1 \%$ formic acid in acetonitrile (B) were the solvents used in preparative HPLC separations.

\subsection{Fungal Material}

Calcarisporium sp. KF525 is a part of the marine fungal strain collection of the Kiel Center for Marine Natural Products. The strain was cryo-conserved using the Microbank system (Pro-Lab).

\subsection{Cultivation}

Calcarisporium sp. KF525 was cultivated in $12 \mathrm{~L}$ of casamino acids glucose medium $\left(0.25 \%\right.$ casein hydrolysate, $4 \%$ glucose $\left.\times \mathrm{H}_{2} \mathrm{O}, 0.01 \% \mathrm{MgSO}_{4} \times 7 \mathrm{H}_{2} \mathrm{O}, 0.18 \% \mathrm{KH}_{2} \mathrm{PO}_{4}, \mathrm{pH} 6.8\right)$ [15]. 2-L Erlenmeyer flasks filled with $0.75 \mathrm{~L}$ medium were used for the culture experiments, which were performed for 24 days at $22{ }^{\circ} \mathrm{C}$ under shaking conditions $(120 \mathrm{rpm})$ in the dark. A circular agar slant (1.8 $\mathrm{cm}$ in diameter) of a preculture served as the inoculum. The preculture was grown on agar plates of modified Wickerham medium $(0.3 \%$ malt extract, $0.3 \%$ yeast extract, $0.5 \%$ peptone from soymeal, $1 \%$ glucose $\times \mathrm{H}_{2} \mathrm{O}, 3 \% \mathrm{NaCl}, 1.5 \%$ agar, $\mathrm{pH} 6.25$ ) [21] over a period of 11 days at room temperature in the dark.

\subsection{Isolation Procedure}

The cultures of Calcarisporium sp. KF525 were separated into mycelium and culture supernatant. An extraction of the culture supernatant with EtOAc yielded a crude extract of $0.92 \mathrm{~g}$. The extract was subjected to the first purification step using a VWR LaPrep HPLC system (gradient: 0 min 10\% B, $17 \mathrm{~min} 60 \% \mathrm{~B}, 22 \mathrm{~min} 100 \% \mathrm{~B}$; flow $100 \mathrm{~mL} \mathrm{~min}^{-1}$; UV detection at $217 \mathrm{~nm}$ ). The purification gave 8 fractions containing the $15 \mathrm{G} 256$ and calcaride components $\left(t_{\mathrm{R}} 12.4,13.2,14.5,15.7,16.2,17.6,18.5\right.$ and $20.6 \mathrm{~min}$ ) of which fraction 8 comprised pure 6 in a yield of $17.7 \mathrm{mg}$. All other fractions were further purified on a Merck-Hitachi LaChrom Elite HPLC system applying reversed-phase chromatography. The purification of fraction 1 gave $17.8 \mathrm{mg}$ of 2 (gradient: $0 \mathrm{~min} 30 \% \mathrm{~B}, 13 \mathrm{~min}$ 
$40 \% \mathrm{~B}$; flow $18 \mathrm{~mL} \mathrm{~min}^{-1}$; UV detection at $220 \mathrm{~nm} ; t_{\mathrm{R}} 6.7 \mathrm{~min}$ ) and fraction 2 afforded $11.8 \mathrm{mg}$ of 5 (gradient: $0 \min 25 \% \mathrm{~B}, 13 \mathrm{~min} 50 \% \mathrm{~B}$; flow $18 \mathrm{~mL} \mathrm{~min}^{-1}$; UV detection at $220 \mathrm{~nm} ; t_{\mathrm{R}} 9.2 \mathrm{~min}$ ). The chromatography of fraction 3 (gradient: $0 \min 30 \% \mathrm{~B}, 15 \min 37 \% \mathrm{~B}$; flow $18 \mathrm{~mL} \min ^{-1}$; UV detection at $220 \mathrm{~nm})$ resulted in $14 \mathrm{mg}$ of purified $4\left(t_{\mathrm{R}} 11.1 \mathrm{~min}\right)$ and semi-pure $9\left(t_{\mathrm{R}} 12.0 \mathrm{~min}\right)$, which was isolated in two additional rounds of purification to give a yield of $23.2 \mathrm{mg}$ (1st, gradient: $0 \mathrm{~min}$ $30 \% \mathrm{~B}, 13 \mathrm{~min} 45 \% \mathrm{~B}$; flow $18 \mathrm{~mL} \mathrm{~min}^{-1}$; UV detection at $220 \mathrm{~nm} ; t_{\mathrm{R}} 9.2 \mathrm{~min}$. 2nd, isocratic: $25 \% \mathrm{~B}$; flow $18 \mathrm{~mL} \mathrm{~min}^{-1}$; UV detection at $\left.210 \mathrm{~nm} ; t_{\mathrm{R}} 23.2 \mathrm{~min}\right)$. Pure $1(17.5 \mathrm{mg}$ ) was obtained from fraction 4 by applying two consecutive steps of preparative HPLC (1st, 0 min 40\% B, $13 \min 65 \% \mathrm{~B}$, flow $18 \mathrm{~mL} \mathrm{~min}^{-1}$; UV detection at $205 \mathrm{~nm}$; $t_{\mathrm{R}} 5.2 \mathrm{~min}$. 2nd, gradient: $0 \mathrm{~min} 30 \% \mathrm{~B}, 10 \mathrm{~min} 61 \% \mathrm{~B}$; flow $18 \mathrm{~mL} \mathrm{~min}^{-1}$; UV detection at $220 \mathrm{~nm} ; t_{\mathrm{R}} 7.6 \mathrm{~min}$ ). Fraction 5 was subjected to two further purification steps yielding $2.9 \mathrm{mg}$ of $\mathbf{1 0}$ (1st, isocratic: $29 \% \mathrm{~B}$, flow $18 \mathrm{~mL} \mathrm{~min}^{-1}$; UV detection at $220 \mathrm{~nm}$; $t_{\mathrm{R}} 21.7$ min. 2nd, gradient: $0 \min 27 \% \mathrm{~B}, 15 \mathrm{~min} 50 \% \mathrm{~B}$; flow $18 \mathrm{~mL} \mathrm{~min}^{-1}$; UV detection at $220 \mathrm{~nm}$; $t_{\mathrm{R}} 12.4 \mathrm{~min}$ ). Fraction 6 contained compounds 7 and $\mathbf{8}$, which were initially eluted isocratically with $42 \% \mathrm{~B}$ (flow $18 \mathrm{~mL} \mathrm{~min}^{-1}$; $\mathrm{UV}$ detection at $220 \mathrm{~nm} ; t_{\mathrm{R}} 11.8 \mathrm{~min}$ ). A subsequent round of preparative HPLC (isocratic: $40 \%$, flow $18 \mathrm{~mL} \mathrm{~min}^{-1}$; UV detection at $210 \mathrm{~nm}$ ) gave purified $7\left(t_{\mathrm{R}} 12.8 \mathrm{~min}\right)$ and 8 $\left(t_{\mathrm{R}} 16.0 \mathrm{~min}\right.$ ) in yields of 14.6 and $5.7 \mathrm{mg}$, respectively. $1.8 \mathrm{mg}$ of compound 3 were isolated from fraction 7 by employing two chromatographic steps (1st, gradient: $0 \mathrm{~min} 50 \% \mathrm{~B}, 13 \mathrm{~min} 80 \% \mathrm{~B}$; flow $18 \mathrm{~mL} \mathrm{~min}^{-1}$; UV detection at $220 \mathrm{~nm}$; $t_{\mathrm{R}} 6.0 \mathrm{~min}$. 2nd, isocratic: $45 \% \mathrm{~B}$, flow $18 \mathrm{~mL} \mathrm{~min}{ }^{-1}$; UV detection at $220 \mathrm{~nm} ; t_{\mathrm{R}} 7.3 \mathrm{~min}$.).

Calcaride A (6): Pale yellow solid, $[\alpha]^{22}{ }_{\mathrm{D}}-23.6\left(c\right.$ 0.195, MeOH), UV (MeOH) $\lambda_{\max }(\log \varepsilon)$ 216 (4.57), 263 (4.27), 302 (3.92) nm; for 1D and 2D NMR data see Table 1; HRESIMS $m / z 661.2503$ $[\mathrm{M}+\mathrm{H}]^{+}$(calcd for $\left.\mathrm{C}_{33} \mathrm{H}_{40} \mathrm{O}_{14}, 661.2491\right)$.

Calcaride B (7): White solid, $[\alpha]^{22}{ }_{\mathrm{D}}-25.3$ (c 0.45, MeOH), UV (MeOH) $\lambda_{\max }(\log \varepsilon) 216$ (4.58), 263 (4.27), 302 (3.92) nm; for 1D and 2D NMR data see Tables 2, 3 and SI; HRESIMS $m / z 677.2435$ $[\mathrm{M}+\mathrm{H}]^{+}$(calcd for $\mathrm{C}_{33} \mathrm{H}_{40} \mathrm{O}_{15}, 677.2440$ ).

Calcaride C (8): White solid, $[\alpha]^{22}{ }_{\mathrm{D}}-7.9$ (c 0.793, MeOH), UV (MeOH) $\lambda_{\max }(\log \varepsilon) 216$ (4.59), 263 (4.30), 302 (3.94) nm; for 1D and 2D NMR data see Tables 2, 3 and SI; HRESIMS $m / z$ 677.2441 $[\mathrm{M}+\mathrm{H}]^{+}$(calcd for $\mathrm{C}_{33} \mathrm{H}_{40} \mathrm{O}_{15}, 677.2440$ ).

Calcaride D (9): White solid, $[\alpha]^{22}{ }_{\mathrm{D}}-71.8\left(c\right.$ 0.98, MeOH), UV (MeOH) $\lambda_{\max }(\log \varepsilon) 216(4.60)$, 263 (4.35), 302 (3.99) nm; for 1D and 2D NMR data see Tables 3, 4 and SI; HRESIMS $m / z 693.2405$ $[\mathrm{M}-\mathrm{H}]^{-}$(calcd for $\mathrm{C}_{33} \mathrm{H}_{42} \mathrm{O}_{16}, 693.2400$ ).

Calcaride E (10): White solid, $[\alpha]^{22}{ }_{\mathrm{D}}-67.3\left(c\right.$ 0.05, MeOH), UV (MeOH) $\lambda_{\max }(\log \varepsilon) 216(4.61)$, 263 (4.35), 302 (3.98) nm; for 1D and 2D NMR data see Tables 3, 4 and SI; HRESIMS $m / z 677.2467$ $[\mathrm{M}-\mathrm{H}]^{-}$(calcd for $\mathrm{C}_{33} \mathrm{H}_{42} \mathrm{O}_{15}, 677.2451$ ).

The process of interconversion of $\mathbf{7}$ and $\mathbf{8}$ was studied by periodical HPLC-UV/MS analyses using the mass chromatograms for quantification of the compounds' purities. For the experiments, purified and dried $\mathbf{7}$ and $\mathbf{8}$ were stored at $4{ }^{\circ} \mathrm{C}$ over a time period of three months. 


\subsection{Antibacterial Assays}

Antibacterial assays were performed using the test strains, Staphylococcus epidermidis (DSM20044), Xanthomonas campestris (DSM 2405) and Propionibacterium acnes (DSM1897). $S$. epidermidis and $X$. campestris were cultivated in Trypticase soy broth (1.2\% Trypticase Soy Broth, $0.5 \% \mathrm{NaCl}$ ) overnight and diluted to an $\mathrm{OD}_{600}$ of $0.01-0.03$. $10 \mathrm{mM}$ DMSO solutions of the compounds were diluted with medium to gain desired test concentrations. $10.5 \mu \mathrm{L}$ of the compound solutions and $200 \mu \mathrm{L}$ of the respective test strain cell suspension were transferred into a 96-well microtiter plate. Microtiter plates with S. epidermidis were incubated for $5 \mathrm{~h}$ at $37^{\circ} \mathrm{C}$ in the dark, while microtiter plates with $X$. campestris were incubated for $6 \mathrm{~h}$ at $28{ }^{\circ} \mathrm{C}$ in the dark. After the addition of $10 \mu \mathrm{L}$ of a resazurin solution as the detective reagent $\left(0.2 \mathrm{mg} \mathrm{mL}^{-1}\right.$ in phosphate-buffered saline), the incubation was continued for another 5-30 min. To evaluate cell viability, the reduction of resazurin to resorufin was determined by measuring the intensity of fluorescence at $560_{\mathrm{Ex}} / 590_{\mathrm{Em}}$ in a Tecan Infinite M200 plate reader.

P. acnes was grown anaerobically (Anaerocult A mini, Merck) in modified PYG medium (DSMZ medium 104) for $48 \mathrm{~h}$ at $37{ }^{\circ} \mathrm{C}$ in the dark. 2-day old cultures were diluted to an $\mathrm{OD}_{600}$ of 0.02 . A volume of $200 \mu \mathrm{L}$ of the cell suspension was transferred to a microtiter plate and mixed with $10.5 \mu \mathrm{L}$ of the test compounds that were treated as described above. After an anaerobic incubation for $48 \mathrm{~h}$ at $37^{\circ} \mathrm{C}$ in the dark, $10 \mu \mathrm{L}$ of bromocresol purple $\left(1 \mathrm{mg} \mathrm{mL}^{-1}\right)$ were added, and the acid production of $P$. acnes was determined by measuring the absorbance at $590 \mathrm{~nm}$ (reference $690 \mathrm{~nm}$ ) using the Infinite M200 plate reader.

The resulting values of the antibacterial assays were compared with a positive control $(10 \mu \mathrm{M}$ chloramphenicol for $S$. epidermidis or $X$. campestris and $1 \mu \mathrm{M}$ chloramphenicol for $P$. acnes) and a negative control (no compound). Minimal inhibitory concentrations (MICs) were defined as more than $20 \%$ inhibition of metabolic activity or acid production in the test strains compared to non-inhibited metabolism in the negative control.

\section{Conclusions}

Five known 15G256 components and five methylated analogs thereof were isolated from Calcarisporium sp. strain KF525: 15G256 $\alpha, \alpha-2, \beta, \beta-2, \pi(\mathbf{1}-\mathbf{5})$ and calcarides A-E (6-10). For the first time, antibacterial properties were detected for this type of natural product. The compounds showed inhibitory bioactivities against Staphylococcus epidermidis, Xanthomonas campestris and Propionibacterium acnes, underlying a tight structure-activity relationship. 15G256 $\alpha$ (1) displayed the strongest inhibition against $S$. epidermidis, with a MIC of $(12.9 \pm 3.6) \mu \mathrm{M}$, and calcaride A (6) exhibited the lowest MIC for X. campestris with $(5.5 \pm 1.3) \mu \mathrm{M}$. P. acnes was specifically inhibited by the compound, $15 \mathrm{G} 256 \pi(5)$, having a MIC of $(14.1 \pm 1.8) \mu \mathrm{M}$.

\section{Acknowledgments}

We gratefully thank K. Schaumann for providing the strain, KF525, and G. Kohlmeyer-Yilmaz, M. Höftmann, as well as F. Sönnichsen for running and processing NMR experiments. This study was 
performed in the framework of the MARINE FUNGI, EU FP7 KBBE program, project no. 265926 at the Kieler Wirkstoff-Zentrum (KiWiZ) at the GEOMAR Helmholtz Centre for Ocean Research, Kiel.

\section{Conflicts of Interest}

The authors declare no conflict of interest.

\section{References}

1. Sutton, B.C. Hyphomycetes from Manitoba and Saskatchewan, Canada; Commonwealth Mycological Institute: Kew, Surrey, UK, 1973; pp. 1-143.

2. Somrithipol, S.; Jones, E.B.G. Calcarisporium phaeopodium sp. nov., a new hyphomycete from Thailand. Sydowia 2006, 58, 133-140.

3. Ji, L.L.; Song, Y.C.; Tan, R.X. A potent feed preservative candidate produced by Calcarisporium sp., an endophyte residing in stargrass (Cynodon dactylon). J. Appl. Microbiol. 2004, 96, $352-358$.

4. Kramer, C.L.; Pady, S.M.; Rogerson, C.T.; Ouye, L.G. Kansas aeromycology II. Materials, methods, and general results. Trans. Kans. Acad. Sci. 1959, 62, 184-199.

5. Watson, P. Calcarisporium arbuscula living as an endophyte in apparently healthy sporophores of Russula and Lactarius. Trans. Brit. Mycol. Soc. 1955, 38, 409-414.

6. Schlingmann, G.; Milne, L.; Carter, G.T. Isolation and identification of antifungal polyesters from the marine fungus Hypoxylon oceanicum LL-15G256. Tetrahedron 2002, 58, 6825-6835.

7. Breinholt, J.; Jensen, G.W.; Nielsen, R.I.; Olsen, C.E.; Frisvad, J.C. Antifungal macrocyclic polylactones from Penicillium verruculosum. J. Antibiot. 1993, 46, 1101-1108.

8. Ito, M.; Maruhashi, M.; Sakai, N.; Mizoue, K.; Hanada, K. NG-011 and NG-012, novel potentiators of nerve growth factor. I. Taxonomy, isolation, and physico-chemical and biological properties. J. Antibiot. 1992, 45, 1559-1565.

9. Roy, K.; Chatterjee, S.; Deshmukh, S.K.; Vijayakumar, E.K.S.; Ganguli, B.N.; Fehlhaber, H.-W. Orbuticin, a new secondary metabolite from Acremonium butyri. J. Antibiot. 1996, 49, 1186-1187.

10. Kondo, H.; Kurama, M.; Nakajima, S.; Osada, K.; Ookura, A.; Suda, H. Estrogenic BE-26263 and its manufacture with Scedosporium apiospermum. Jpn. Kokai Tokkyo Koho JP 05032658, 1993.

11. Arai, M.; Tomoda, H.; Okuda, T.; Wang, H.; Tabata, N.; Masuma, R.; Yamaguchi, Y.; Omura, S. Funicone-related compounds, potentiators of antifungal miconazole activity, produced by Talaromyces flavus FKI-0076. J. Antibiot. 2002, 55, 172-180.

12. Zhou, Z.-Y.; Liu, R.; Jiang, M.-Y.; Zhang, L.; Niu, Y.; Zhu, Y.-C.; Dong, Z.-J.; Liu, J.-K. Two new cleistanthane diterpenes and a new isocoumarine from cultures of the basidiomycete Albatrellus confluens. Chem. Pharm. Bull. 2009, 57, 975-978.

13. Ito, M.; Tsuchida, Y.; Mizoue, K.; Hanada, K. NG-011 and NG-012, novel potentiators of nerve growth factor. II. The structure determination of NG-011 and NG-012. J. Antibiot. 1992, 45, 1566-1572.

14. Silber, J.; Ohlendorf, B.; Labes, A.; Näther, C.; Imhoff, J.F. Calcaripeptides A-C, cyclodepsipeptides from a Calcarisporium strain. J. Nat. Prod. 2013, 76, 1461-1467. 
15. Stevens, R.B. Mycology Guidebook; University of Washington Press: Seattle, WA, USA, 1974; pp. 1-703.

16. Buckingham, J. Dictionary of Natural Products on DVD, Version 21:1; CRC Press Taylor and Francis Group: London, UK, 2012.

17. Walle, T.; Ta, N.; Kawamori, T.; Wen, X.; Tsuji, P.A.; Walle, U.K. Cancer chemopreventive properties of orally bioavailable flavonoids - methylated versus unmethylated flavones. Biochem. Pharmacol. 2007, 73, 1288-1296.

18. Liu, Y.; Salvador, L.A.; Byeon, S.; Ying, Y.; Kwan, J.C.; Law, B.K.; Hong, J.; Luesch, H. Anticolon cancer activity of largazole, a marine-derived tunable histone deacetylase inhibitor. J. Pharmacol. Exp. Ther. 2010, 335, 351-361.

19. Li, J.W.-H.; Vederas, J.C. Drug discovery and natural products: End of an era or an endless frontier? Science 2009, 325, 161-165.

20. Grüschow, S.; Rackham, E.J.; Goss, R.J.M. Diversity in natural product families is governed by more than enzyme promiscuity alone: establishing control of the pacidamycin portfolio. Chem. Sci. 2011, 2, 2182-2186.

21. Wickerham, L.J. Taxonomy of Yeasts; US Dept. of Agriculture: Washington, DC, USA, 1951; pp. 1-56.

(C) 2013 by the authors; licensee MDPI, Basel, Switzerland. This article is an open access article distributed under the terms and conditions of the Creative Commons Attribution license (http://creativecommons.org/licenses/by/3.0/). 